\title{
The Relationship between Carotene Concentration and Vitamin A Activity of Carrots for Rats
}

\author{
By V. H. BOOTH \\ Dunn Nutritional Laboratory, University of Cambridge and Medical Research Council
}

(Received 28 February 1947)

The vitamin A values of plant foodstuffs, as found by biological tests with rats, are often lower than would have been expected from the results of chemical estimations of the carotene content. The causes of this discrepancy presumably lie mainly in a less complete absorption of carotene from vegetables than from the oily solution in which the international $\beta$-carotene standard is administered, and in the inability of the chemical methods, as commonly applied, to discriminate between $\beta$-carotene and isomers of lower biological activity. The present paper is concerned with the experimental evaluation of the ratio between biological and chemical values for carrots.

\section{Mode of expressing the biological and chemical results in units}

The international unit of vitamin $A$ is defined as the vitamin A activity of $0.6 \mu \mathrm{g}$. of pure $\beta$-carotene (League of Nations, I934). When the carotene content has been determined by chemical means the results are most commonly expressed by weight in mg. or $\mu \mathrm{g}$., but when the vitamin A potency has been determined by biological means the quantities are usually expressed in international units (i.u.). As this paper is concerned with the numerical relationship of the values obtained by the two methods, it is convenient for purposes of comparison to express the chemical values also as i.u. This is done by dividing the number of $\mathrm{mg}$. of carotene found chemically by the value 0.0006 , but, in order to distinguish the results of chemical tests expressed in this way from the results of biological tests, the term 'ch.i.u.' will be used in the former case.

The relationship between biological and chemical values has in the past usually been expressed as the chemical/biological ratio, i.e. as ch.i.u./i.u. The biological value observed may, however, vary with the technique according, for instance, to whether rats or other animals are used, to the method of preparation of the diet and supplement, and to whether growth or some other criterion is selected for measurement. The chemical value, on the other hand, can be determined with much more accuracy. Therefore, it seems more rational to express the biological value as a percentage of the chemical value, i.e. i.u. $\times$ roo/ch.i.u. This is a similar relationship to that called the 'biological value' by Guggenheim (1944).

Values previously reported for the vitamin $A$ potency of carrots

Results of other workers for biological determinations of the vitamin A value of carrots appear in Table I. The values of Scoular, Bellew, Carl \& Dozier (1943), and of Wilson, Ambrose, DeEds, Dutton \& Bailey (1946) were based on the dry weight. 
To make these values comparable with the others in the table they have been divided by 8 on the assumption that the fresh carrot contains $87.5 \%$ of water. The doses used by Coward \& Morgan (1935) were high; their value for August carrots of I 900 i.u./IOO g., the lowest in the list, is consequently only a minimum value. From the limited data of Smith \& Otis (194I) values of 10,000 for pale orange, and 17,000 for red, carrots may be obtained by calculation; their experiments do not, however, appear to have been done under standard conditions; there was, for instance, only a small number of rats in certain groups.

Table I. Values reported by other workers for the vitamin A activity of carrots determined biologically, with values obtained chemically for the same material where such tests were also made

\begin{tabular}{|c|c|c|c|c|}
\hline \multirow[b]{2}{*}{ Authority } & \multicolumn{3}{|c|}{ Carotene content/I00 g. fresh wt. } & \multirow[b]{2}{*}{$\frac{\text { Biol. value } \times \text { roo }}{\text { Chem. value }}$} \\
\hline & \multicolumn{2}{|c|}{$\begin{array}{l}\text { Determined biologically } \\
\text { (i.u.) }\end{array}$} & $\begin{array}{l}\text { Determined } \\
\text { chemically } \\
\text { (ch.i.u.)* }\end{array}$ & \\
\hline Coward \& Morgan (1935) & & 1,900 & - & - \\
\hline Hanning (1936) & & 6,500 & 一 & - \\
\hline Scheunert \& Wagner (1940) & & 10,000 & 8,000 & I 25 \\
\hline $\begin{array}{l}\text { Booher, Hewston \& Marsh } \\
\text { (I94I) }\end{array}$ & & 10,700 & - & - \\
\hline Smith \& Otis (194I) & $\left.\begin{array}{ll}\text { Yellow carrots } & \text { ro,ooo } \uparrow \\
\text { Red carrots } & 17,000 \dagger\end{array}\right\}$ & $13,500 \dagger$ & $\left.\begin{array}{r}2,000 \\
23,000\end{array}\right\} 12,500$ & 108 \\
\hline $\begin{array}{l}\text { Sherman, H. C. (quoted by } \\
\text { Graves, 1942) }\end{array}$ & & 2,500 & - & - \\
\hline $\begin{array}{l}\text { Scoular, Bellew, Carl \& } \\
\text { Dozier (1943) }\end{array}$ & & $2,500 \dagger$ & - & - \\
\hline $\begin{array}{l}\text { Wilson, Thomas \& DeEds } \\
\text { (1943) }\end{array}$ & & 20,500 & 16,800 & 122 \\
\hline Guggenheim (1944) & & 7,100 & 12,500 & 57 \\
\hline Oser \& Melnick (1945) & $\left.\begin{array}{l}6,400 \\
3,600\end{array}\right\}$ & 5,000 & $\left.\begin{array}{r}10,300 \\
5,040\end{array}\right\} 7,670$ & 66 \\
\hline $\begin{array}{l}\text { Callison \& Orent-Keiles } \\
\text { (1945) }\end{array}$ & & 7,000 & - & - \\
\hline \multirow{2}{*}{$\begin{array}{l}\text { Wilson, Ambrose, DeEds, } \\
\text { Dutton \& Bailey (1946) }\end{array}$} & & $19,200 \dagger$ & 21,700 & 88 \\
\hline & $\mathrm{Me}$ & in 8,870 & & 94 \\
\hline
\end{tabular}

American usage prefers cod-liver oil to $\beta$-carotene as standard for vitamin A. According to evidence from various sources, summarized by Morton (1942), the U.S.P. reference cod-liver oil has lost part of its activity: hence biological values determined against it are likely to be high. Confirmation comes from Callison \& Orent-Keiles (1945) who have made both comparisons: the average result of four bio-assays on carrots against the U.S.P. cod-liver oil was I r, 000 i.u./ 100 g., and against $\beta$-carotene 7000 . The authors give the mean of the differences by which the results obtained against the reference oil are too high as $34 \%$ but, if the calculation is made on the basis of the values obtained against carotene as standard rather than of that obtained against the reference oil, the difference is $54 \%$. Since some of the values in Table I were obtained against the U.S.P. reference oil they must also presumably be too high in varying degree according to the date of the assay. 
Another probable cause of error in biological tests. on carrots is that the basal diet has not always included vitamin $\mathrm{E}$, although this is a dietary essential for the rat and is known to play a part in vitamin A metabolism and to influence the requirement (Moore, Martin \& Rajagopal, 1939; Hickman, Harris \& Woodside, 1942; Guggenheim, 1944; Moore, 1945).

Seasonal variations in carotene content have not always been considered. According to Barnes (1936), Werner (1940), and Booth \& Dark (unpublished), maturity is not reached until autumn. Carotene values in early August, for instance, may be only $50-80 \%$ of the mature values. Consequently a biological value, unaccompanied by a description of the carrots including the date of harvesting, or by a chemical value, has little meaning.

The average of all the biological values in Table $\mathrm{I}$ is $887 \mathrm{O}$, but in view of the above considerations its accuracy is doubtful. In six cases only are values given by the same authors for results obtained by both chemical and rat-growth methods. The average biological/chemical percentage for these cases is 94 . On the other hand, Fraps \& Meinke (r 945 ), using a liver-storage method, found the percentage to be 30 . Graves (1942) suggests that the chemical/biological ratio may be as high as 6 , so that the biological/chemical percentage would be I7. Smith \& Otis (I94I) report a wide variation with carrots of different colour.

For the carotene content of carrots determined chemically, more than forty references have been found in the literature. The average value is $9 \mathrm{mg}$. ( $15,000 \mathrm{ch} . \mathrm{i} . \mathrm{u}$.) $/ 100 \mathrm{~g}$. but, because of immaturity and inappropriate methods of assay, this value is too low (for discussion see Dark \& Booth, 1946). However, for comparison with the average of the published biological values, it seems appropriate to use it to compute a percentage. This is $8870 \times 100 / 15,000=59 \%$; the degree of accuracy is unknown but, judged by the results described below, this value is nearer the truth than the value of $94 \%$ mentioned above, obtained from the results of various direct comparisons.

\section{METHODS}

\section{Determination of vitamin $A$ potency by the rat-growth method}

Rats of both sexes were weaned on to a vitamin A-free diet having the percentage composition: extracted casein (Glaxo $\mathrm{C} / \mathrm{E}$ or $\mathrm{A} / \mathrm{E}$ ) 17 , arachis oil 13 , sucrose 53 , dried yeast $\mathrm{r}_{3}$, salt mixture 4 . Each rat received also $2 \mathrm{mg}$. racemic $\alpha$-tocopheryl acetate mixed with $40 \mathrm{mg}$. (r20 i.u.) of Radiostol (synthetic vitamin D of the British Drug Houses Ltd.) once a week. From about 25 days of age the rats were kept in individual cages and weighed at least twice weekly. Immediately they had ceased gaining weight they were given graded doses of cooked or raw carrot or of international standard carotene. Two groups received 5 and 7.5 i.u. standard carotene, freshly diluted with arachis oil containing $0.01 \%$ quinol, twice a week. The oil was given directly into each rat's mouth from a dropping pipette. Three other groups were given closely graded doses of various specimens of carrot predicted to give a response approximately equal to that given by the two doses of standard. For an average carrot these were 16,22 and 30 ch.i.u. carotene for each of the two doses per week, 
less for pale carrots, and more for deep red ones, since the carotene in the latter proved to be less well utilized. Experience has emphasized the necessity for the doses to be closely graded because accurate computation of the result is only possible if the responses to the standard and to the unknown overlap. Growth rates during 4 weeks of dosing were calculated from growth curves. The averages for males and females were calculated separately, and the means of these pairs of averages were used for plotting dose-response curves. One or more of the doses of carrot always gave a growth response close to or between the responses to the two doses of standard. The activity was calculated by direct comparison of the dose of carrot giving the same response as an interpolated dose of standard.

Because cut carrot loses water to air, it is important that sampling and weighing should be done rapidly. The total supplement for a group of rats was, therefore, weighed and then divided into similar sector-shaped pieces, the doses being equalized by inspection. Non-uniformity would be negligible when spread over the eight doses for the experimental period. At the same time, sectors were cut and weighed for chemical analysis.

For tests with cooked carrot the pieces for both biological and chemical tests were placed in separate test-tubes, which were immersed in boiling water for $45 \mathrm{~min}$. A few drops of water were added where appropriate to counter desiccation.

For the chemical and biological tests with raw carrots, the samples were prepared in the same way but without cooking.

\section{Estimation of vitamin A potency by the liver-storage method}

This technique was used as a confirmatory one. The procedure was broadly similar to that described by With (1942), Guggenheim (1944), Fraps \& Meinke (1945) and others, except that the doses were larger and were given over a longer period. Rats depleted of vitamin A were divided into groups which were matched as far as possible in litter, sex and weight. Each group was given carrot, sampled as described above, or carotene in oil, on 6 days a week for 3 weeks. Two days after the last dose was consumed the rats were killed with coal gas, and the vitamin A content of each whole liver was determined by the method of Davies (1933) (see also Davies \& Moore, 1939). With a dose of $0.8 \mathrm{mg}$. ( 1330 ch.i.u.) $\beta$-carotene, storage was negligible under the conditions of the present experiment, so that this was the minimum dose suitable for the purpose. Females stored more vitamin $\mathrm{A}$ in relation to the dose than males. The average for each sex was, therefore, worked out separately, and the means of these averages were used in calculating all results.

\section{Estimation of carotene excreted by rats in their faeces}

Rats on the vitamin A-free diet were kept in individual cages with wire-grid bottoms beneath which the droppings were collected on sheets of paper. Supplements were given as described above. The faeces from each rat were softened with water and extracted with a mixture of light petroleum and acetone in the proportion of $3: 2$ by volume, next with acetone and then several times with the mixture. From the combined extracts the acetone was washed with water, leaving fats and pigments in 
the light petroleum. The fat was removed by cold saponification and washing. The carotene was freed from other pigments with aqueous diacetone alcohol or on alumina$\mathrm{Na}_{2} \mathrm{SO}_{4}$ and the amount was determined in the photometer (Booth, $1945 a$ ).

Small amounts of a carotene-like pigment are always found in faeces even after prolonged subsistence on a carotenoid-free diet (see for instance Kemmerer \& Fraps, 1938; Ramasarma \& Hakim, 1942; Guggenheim, 1944). Several experiments have been done by the present author to evaluate this residual pigment or 'blank'. It was found to be approximately proportional to body-weight and averaged $\mathrm{I}^{\circ} \mathrm{I}$ and $0.8 \mu \mathrm{g}$. 'carotene' $/ 24 \mathrm{hr}$. for male and female rats, respectively, at a body-weight of $200 \mathrm{~g}$. The amount of this residual pigment was subtracted from the total carotene recovered from the faeces, and the percentage of the ingested carotene which had disappeared was calculated separately for each rat. In none of the experiments in which both bucks and does were used was there any significant sex difference in this percentage disappearance. Accordingly, it was deemed safe to weight experiments on females only equally with those on both sexes.

Up to 3 days are required for passage of unabsorbed food from mouth to anus in the rat. Usually no food carotene could be detected in the faeces later than $60 \mathrm{hr}$. after the meal but, if the dose contained over $400 \mu \mathrm{g}$., small amounts were sometimes detected $72 \mathrm{hr}$.. afterwards. Hence faeces had to be collected for long enough to recover all the excreted carotene, but not for longer than was necessary, because of the progressive increase in the correction needed for the 'blank' or residual carotene. A suitable period for most ordinary intakes was from a few hours after dosing until $65 \mathrm{hr}$. after the dose, or after the second dose if two were given. Since the loss of carotene in stored faeces was found to be only $17 \%$ in 15 days at room temperature, it was assumed that loss during the period of collection was negligible. The possibility of destruction within the alimentary canal was not of course excluded by this finding.

\section{Chemical determination of carotene content of carrots}

The carrots were assayed chemically for total carotene, most of it $\beta$ - and $\alpha$-carotenes, by the sector method (Booth, $1945 b$ ). Carotenols (xanthophylls) were removed in some cases with diacetone alcohol, in others with alumina- $\mathrm{Na}_{2} \mathrm{SO}_{4}$ mixture. No significant difference was found when both methods were used with carrot extracts. The same carrots as were given to rats were also tested chemically on each dosing day. Colorimetric determinations were done on the Pulfrich gradation photometer calibrated with the international standard carotene, by which means a true comparison was obtained between biological and chemical values. In selected cases the carotene was separated into its two major constituents, the $\beta$ - and $\alpha$-groups, by first determining the content of total carotene with the alumina- $\mathrm{Na}_{2} \mathrm{SO}_{4}$ technique, then washing out the acetone from the light petroleum solution, and separating the pigments on magnesium oxide.

\section{Test material}

The carrots (Daucus carota L.) used were grown on various soils in south-east England. They were of three types, classified according to their concentration of carotene. (I) Very young, immature, yellow roots, weighing only some $8 \mathrm{~g}$. each and 
having about $3.3 \mathrm{mg}$. (5500 ch.i.u.) carotene/roo g. fresh weight. (2) 'Ordinary' carrots of the commonly grown varieties having at maturity about 9-18 mg. ( $15,000-$ $30,000 \mathrm{ch} . \mathrm{i} . \mathrm{u}$.)/100 g. The average value has been found to be $12.4 \mathrm{mg}$. (Dark \& Booth, 1946). (3) The exceptionally rich red carrots of the long varieties, bred and described by Dark \& Booth (r946), having about $50 \mathrm{mg}$. (80,000 ch.i.u.)/roo g.

\section{RESULTS}

\section{Results of the rat-growth tests in relation to the results of the chemical tests}

Parallel determinations of carotene content were made by the rat-growth method and by the chemical method on ten samples of carrots having a wide range of carotene values. The results are shown in Table 2 . The dates show to the nearest month when

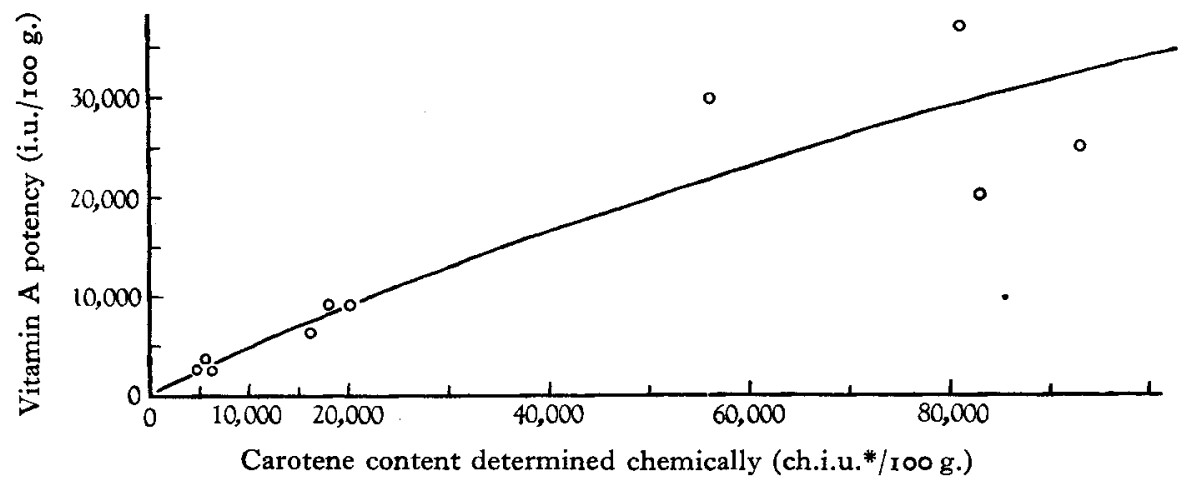

Fig. I. Relationship between the carotene content of carrots determined chemically and the vitamin A potency determined biologically by growth tests with rats.

* For explanation see p. I I3.

dosing was in progress. In some cases carrots were freshly dug for a test; in others they were lifted during the winter, stored in burnt soil for a month and then in a closed container in the refrigerator. Under these last-named conditions carrots can be kept healthy for many months with only negligible change in weight.

The limits of error in most of the bio-assays are $65-155 \%$ with $P=0.95$. It is evident from inspection of Fig. I that the results are well within these limits. Exact computation of the error is impossible because of a deterioration of the international standard carotene, which was believed to have taken place during the experiment (see Discussion, p. I23).

The values obtained by biological assay expressed as percentages of the chemical values are shown in the eighth column of Table 2. The variations in this percentage are presumably due to differences in the experimental conditions caused by the variety, mode of cultivation, age and state of the carrots, whether they were cooked or raw, in the proportion of $\beta$-carotene they contained, in the season of the year, in the freshness of the standard, and in the responses of the rats. The number of experiments, however, justifies the construction of the curve shown in Fig. I. The relationship between the values for vitamin A potency obtained by growth tests and the carotene values obtained by chemical tests is not quite linear, the biological/chemical percentage 
Vol. I

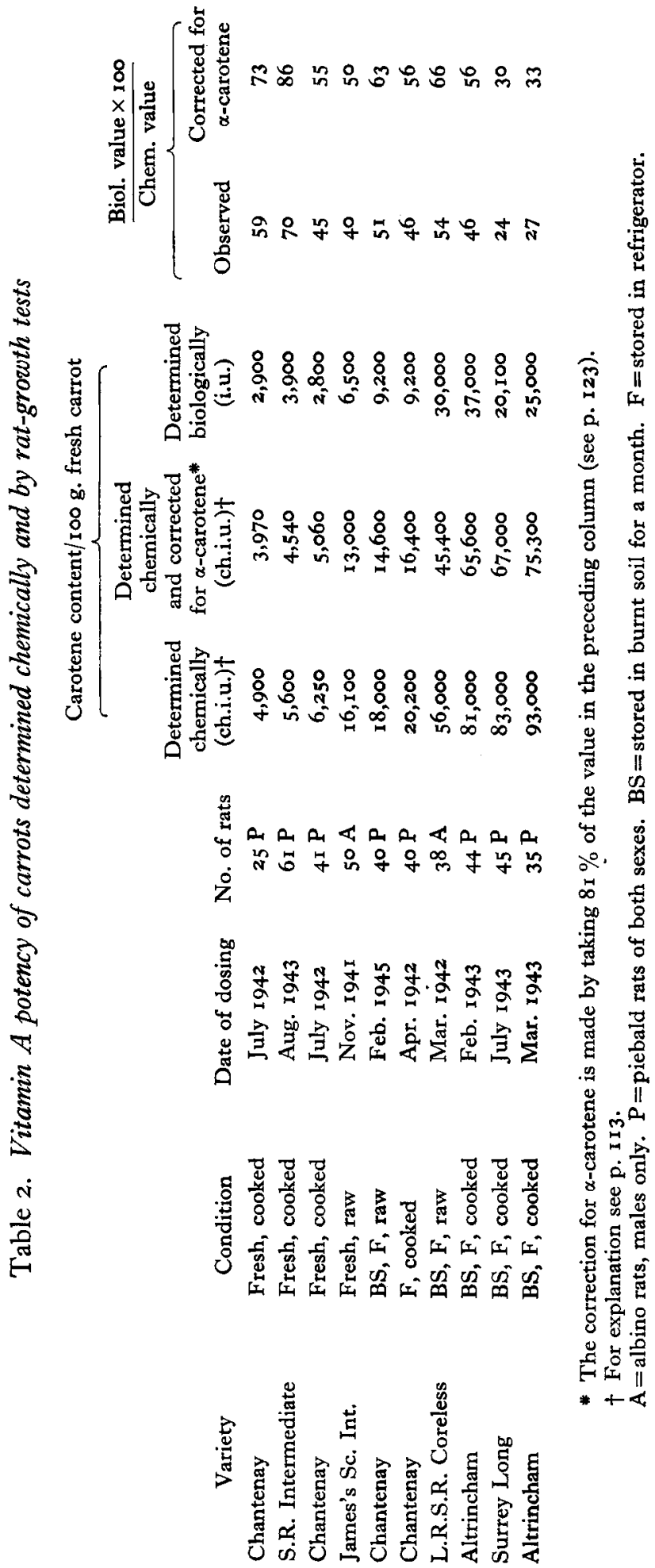

$\stackrel{5}{5}$ 
falling slightly with increasing concentration of carotene in the roots. To take an extreme instance, an exceptionally rich carrot having 100,000 ch.i.u./100 g. with a vitamin A activity of $34 \%$ has not ro but only $7 \cdot 1$ times the biological value of an unusually poor carrot having I0,000 ch.i.u./100 g. and a vitamin A activity of $48 \%$.

\section{Liver storage of vitamin $A$ in relation to the type of carrot consumed}

In order to confirm the existence of the variation just mentioned in the biological value of carotene with the variation in its concentration within the carrot, a direct comparison was made between 'ordinary' and 'high-carotene' carrots by the liverstorage technique. In four experiments I40 piebald rats were dosed with carrot and then killed. In Fig. 2 the average vitamin A content of the livers (estimated in-

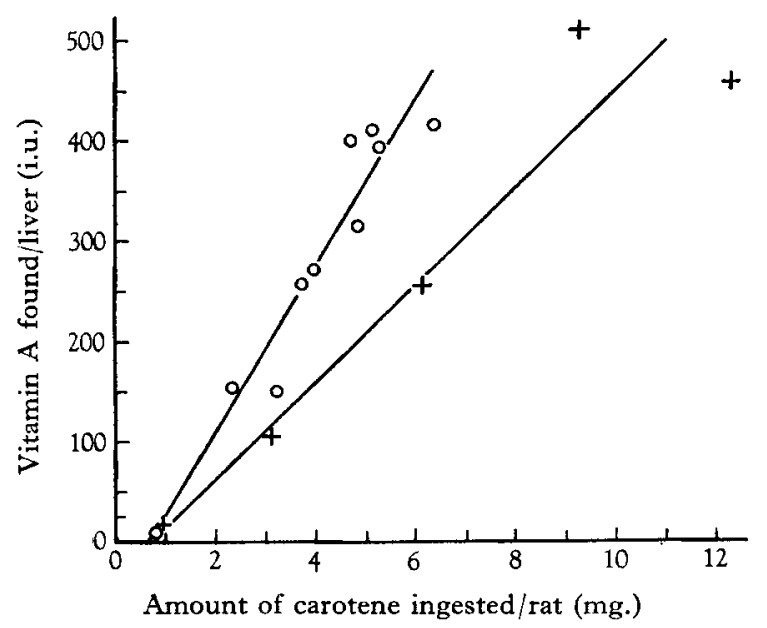

Fig. 2. Relationship between the amount of carotene eaten and the amount of vitamin $A$ found in the livers of rats. $O$ Carotene from carrots with about il mg./ $100 \mathrm{~g}$; + carotene from carrots with about $50 \mathrm{mg} . / 100 \mathrm{~g}$.

dividually) is plotted against the dose of carotene ingested for the two types of carrot. Each point represents the average of the values for a group of several male and female rats. The dose-response curves are straight lines. The slope of the line for ordinary

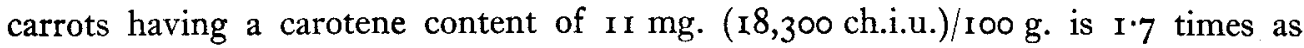
steep as the slope of the line for high-carotene carrots with $50 \mathrm{mg}$. $(83,000 \mathrm{ch} . \mathrm{i} . \mathrm{u}$.)/ $/ \mathrm{oo} \mathrm{g}$. The carotene in the less rich carrots was, therefore, $I \cdot 7$ times as effective for promoting the storage of vitamin $A$ as the same amount of carotene from the richer carrots. The corresponding relationship between these two types of carrot, computed on the basis of the growth tests from the curve in Fig. I, is $\mathrm{I} \cdot 4$. The liver-storage results, therefore, support the growth results; the agreement is not exact, but it is noteworthy that the amounts of carrot ingested in the storage experiments were nearly roo times those ingested in the same time in the growth experiments. In the latter the intake was necessarily suboptimal and the rats were to that extent abnormal, while in the former a rat may have had to consume nearly half its own weight of carrot in 3 weeks.

When tested by the liver-storage technique, carotene in ordinary carrots had about 
the same vitamin value as it had in oil. This fact may appear to be inconsistent with the results of the growth tests. The explanation, which is outside the scope of the present work, appears to be connected with the great size of the doses and the consequently increased intake of accessory factors in small amount. The comparison of one carrot with another by the liver-storage method is, however, unlikely to be affected; if it were, the dose-response curves would not both be straight lines.

\section{Intestinal absorption of carotene from oil and from different kinds of carrots}

When food containing carotene is ingested, some carotene can always be recovered in the faeces. The carotene which disappears during the passage of food through the gut is usually assumed to have been absorbed but, until this is proved, the term 'disappearance' seems preferable to 'absorption'. Moreover, it is generally supposed that the smaller absorption of carotene from carrots than from oil explains the lower biological value of carotene in the former.

Table 3. Some published results of studies on the 'absorption' of carotene by rats from carrots and from oil

Source of caroten
Carrot
Carrot
Carrot
Oil
Oil
Oil
Oil
Oil
Oil

Proportion of ingested carotene not excreted

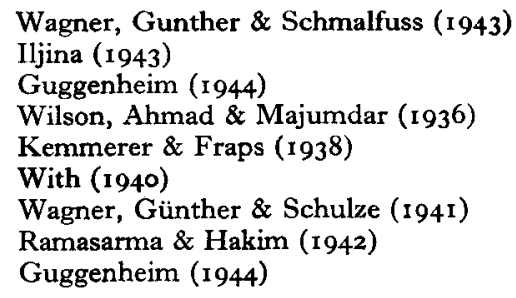

Authority
Wagner, Gunther \& Schmalfuss (1943)
Iljina (1943)
Guggenheim (I944)
Wilson, Ahmad \& Majumdar (1936)
Kemmerer \& Fraps (1938)
With (1940)
Wagner, Günther \& Schulze (1941)
Ramasarma \& Hakim (1942)
Guggenheim (1944)

There are various reports in the literature of studies on the alimentary absorption of carotene by rats. Some of them are set out in Table 3. The average percentage absorption of carotene was 42 from carrots and 76 from oil. The proportion of carotene which disappeared from carrots was thus only $55 \%$ of that which disappeared from oil. In most of these studies no special care was taken to ensure that the intake of vitamin $\mathrm{E}$ was adequate. It seemed advisable, therefore, to check the validity of the relationship thus arrived at, by using rats sufficiently supplied with vitamin $\mathrm{E}$.

A group of twelve rats was given doses of carrot containing varying amounts of carotene over the range from 9 to $64^{\circ} \mu \mathrm{g}$. The percentage which disappeared was greatest from small doses. This fall in efficiency of absorption with increasing dose, at the low end of the range, was several times confirmed. The accuracy with low doses is, however, seriously impaired by the relative size of the 'blank' correction. For this reason in most of the experiments the doses given were large enough to reduce the blank to insignificance. These doses were much higher than those used for the growth tests but, since the prime object of this series of experiments was to compare carotene in carrots with carotene in oil, it was essential that the dose levels for the two should be comparable. 
The results of several such experiments are summarized in Table 4. It will be seen that much the greatest amount of carotene disappeared from oily solution, the average being $73 \%$. From pale yellow carrots the efficiency of absorption was greater than from the deep red, high-carotene type. Cooked carrots were a little better than raw, but the difference was not great. For 'ordinary' carrots containing $12 \cdot 4 \mathrm{mg}$.

Table 4. 'Disappearance' of carotene during the passage of food through

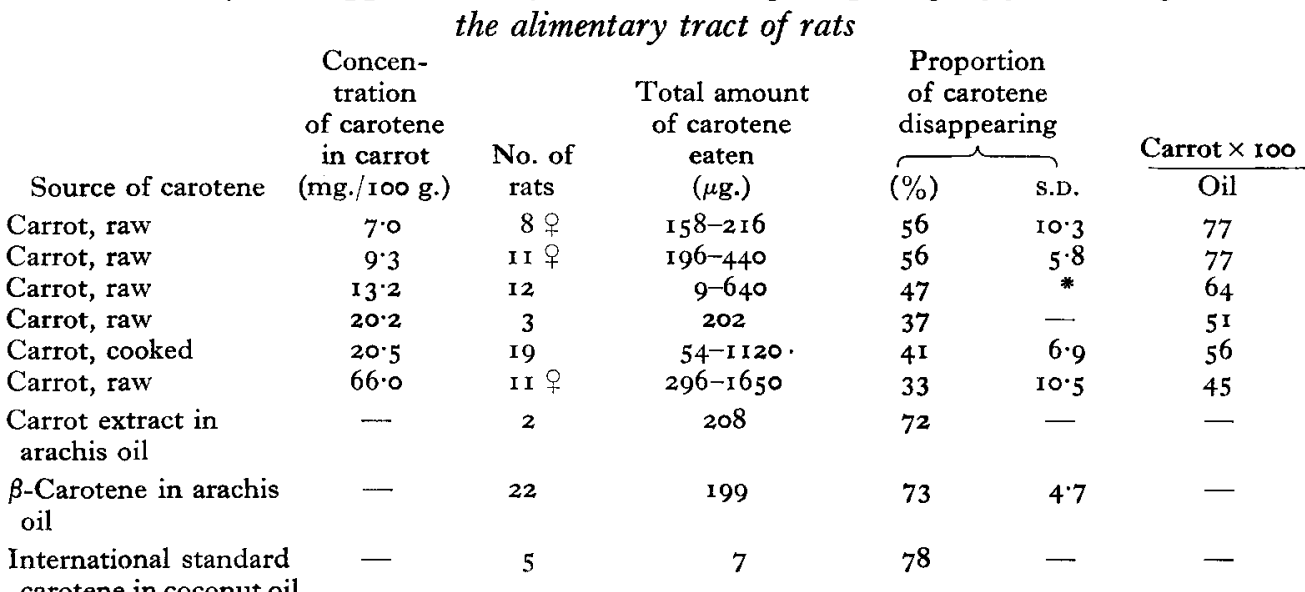

Weighted mean for carotene in oil 73

* The percentage varied with the dose level; see p. I2I.

carotene/roo g. the disappearance was calculated, from a curve constructed from the data in Table 4 , to be about $47 \%$. The proportion of carotene absorbed from ordinary carrots was thus $64 \%$ of the proportion absorbed from oil. Table 4 shows the standard deviation of the mean percentage disappearance in each case in which the number of animals in a group justified its calculation. The mean of the standard deviations, weighted by the number of animals in a group, was $\pm 6 \cdot 94$.

\section{DISCUSSION}

\section{Variation in the biological/chemical percentage according to the type of carrot}

The results obtained by the various methods agree in showing that the biological value for rats of the carotene of carrots varied (but in opposite sense) with the concentration of carotene in the carrot, though the variation was small within the range of concentration of ordinary carrots. If the early varieties are included, the limits for the biological/chemical percentage are approx. 42-52. Differences in digestibility might account for a part of the variation since the less rich carrots were young and fresh, while the richer ones were old and stored.

\section{Contribution made to the biological activity by $\alpha$-carotene}

In this paper 'carotene', which is generally $90 \%$ of the total carotenoids, means the complete mixture of $\beta-, \alpha$ - and $\gamma$-carotenes and their $c i$ isomers as it occurs in carrots, but excludes carotenols. According to Harper \& Zscheile (1945) the $\beta$-isomer 
represents $54 \%$ of the carotene; Sadana \& Ahmad (I947) found $56 \%$; Mackinney \& Fratzke (1947) $58 \%$; Kemmerer \& Fraps (r945) 60\%; Fujita \& Ajisaka (194I) 6r \%; Kemmerer, Fraps \& Meinke (1945) 62\%; and Broge (1945) $76 \%$. We have found well over $60 \%$. The average is, therefore, unlikely to differ much from $62 \%$. The remaining $38 \%$ is principally $\alpha$-carotene but includes small amounts of other isomers. Wilkinson (I94I) found that $\alpha$-carotene from palm oil had half the biological activity of $\beta$-carotene. If the vitamin $A$ activity of the above-mentioned $38 \%$ is taken as half that of the same amount of $\beta$-carotene, the activity of the total carotene from carrots should be $8 \mathrm{I} \%$ of the activity of the same amount of $\beta$-carotene. In order to express the values for total carotene in terms of $\beta$-carotene, the chemical and biological values in columns 5 and 8 , respectively, in Table 2 have been recalculated on this basis, and the results appear in columns 6 and 9. Elsewhere throughout this paper the observed values for total carotene have not been so corrected.

\section{Part played by the inefficiency of intestinal absorption}

The lower activity of $\alpha$-carotene accounts only partly for the divergence of the biological/chemical percentage for carrots from Ioo. The remainder of the divergence is generally assumed to be due to lower alimentary absorption of carotene from plant tissues than from oil. For ordinary carrots of the type containing $12 \cdot 4 \mathrm{mg}$. $(20,700$ ch.i.u. $) / \mathrm{ro0}$ g. the biological/chemical percentage derived from Fig. I is $46 \cdot 5$. The correction for $\alpha$-carotene raises the percentage to 57. The absorption (as assessed by alimentary disappearance) of carotene from ordinary carrots was only $64 \%$ of the absorption of carotene from oil. These two percentages may be compared. The first represents utilization, and the second absorption, of carotene from carrot in terms of carotene from oil. The values (57 and 64 ) are sufficiently close to warrant the statement that we can account for most of the difference between chemical and biological values for carotene in carrots, that is, for the low utilization of the carotene in the latter. Whether the remaining $7 \%$ is covered by experimental error or by a third factor cannot at present be settled. It is noteworthy that the values for the biological/ chemical percentage, the liver storage and the efficiency of absorption, all rise when the concentration of carotene in carrots is low. No doubt the last of these controls the other two.

\section{Deterioration of the international standard solution during the experiments}

Reference has been made to a loss of activity by the international standard carotene which took place during the work. Every precaution was taken in storing the standard carotene and using it in a fresh condition, but the colorimetric values suggested that most samples had suffered some loss. The occurrence of this destruction was established by direct comparison with pure $\beta$-carotene and by adopting for the colour test a value of $255^{\circ}$ for $E_{1 \mathrm{om}}^{1 \%}$ at $450 \mathrm{~m} \mu$. in light petroleum, arrived at after consideration of data of Devine, Hunter \& Williams (1945). The average amount of deterioration was about $10 \%$. In the present work the same samples of international standard carotene were used both for chemical and biological assays, so that the small amount of deterioration in the standard would scarcely affect the observed biological/chemical percentage. 
The true biological values of carrots, if estimated against fresh pure $\beta$-carotene, would, however, be proportionately lower than the values reported here, and each biological/chemical percentage, therefore, really belongs to a slightly lower carotene concentration. In other words, the scale for both the chemical and biological values in Fig. I ought to be expanded, or the curve ought to be contracted downwards and towards the left, but, since the shape of the curve would be unaffected, its usefulness remains. In the practical application of the curve this effect makes very little difference, as the following example shows. From Fig. I it may be seen that the biological value for ordinary mature carrots of commonly grown varieties having $12 \cdot 4 \mathrm{mg}$. (20,700 ch.i.u.) total carotene/100 g. is $9600 \mathrm{i} . \mathrm{u} . / \mathrm{l} 00 \mathrm{~g}$., and hence the biological/chemical percentage is 46.5 . The result of a $10 \%$ contraction of the curve at a true, chemical value of 20,700 ch.i.u. would be to shift the percentage from 46.5 to $46 \cdot 0$ and the biological value from 9600 to 9500 . This small change is of course due to the fact that the curve is not linear. Even had the standard deteriorated by more than $10 \%$ it seems unlikely that the percentage at this level would be less than 44 . There is also the possibility that a loss of potency of the standard might have occurred through trans $\rightarrow$ cis isomerization. Taking this into consideration the biological value suggested for mature carrots is $9000 \mathrm{i} . \mathrm{u} . / \mathrm{ro0} \mathrm{g}$.

\section{Application of the results to human diets}

The results in this paper are derived from experiments on rats, and the same is true of the vitamin A values attributed to most foods. The possibility exists, however, that carrots have a different relative vitamin $\mathrm{A}$ value for man.

\section{SUMMARY}

I. The values found in the literature for the carotene content determined chemically, and the vitamin A potency determined biologically, in mature carrots were inadequate for determining the ratio of these two properties to one another.

2. In the present paper, this ratio is called the biological/chemical percentage, and is defined as one hundred times the biological value divided by the chemical value.

3. The carotene content was determined chemically, and the vitamin A potency biologically by the rat growth method, against the international standard solution of $\beta$-carotene for ten samples of seven varieties of carrots.

4. The carotene content determined chemically ranged from 4900 to 93,000 ch.i.u.*, and the biological value from 2900 to 37,000 i.u./100 g. wet tissue. The biological value tended to be less in proportion as the concentration in the carrot increased, the biological/chemical percentage ranging from 24 to 70 ; for ordinary carrots with a concentration of carotene of $12.4 \mathrm{mg}$. $/ \mathrm{ro0} \mathrm{g}$. this percentage was 46 .

5. A curve was constructed from which may be read the vitamin A potency, for rats, of any carrots having a known carotene content determined chemically.

6. The existence of an inverse relationship between the biological potency and the concentration of carotene in carrots was confirmed by measuring the amount of

* For explanation see p. II3. 
vitamin A stored in the liver of rats dosed with two types of carrot, one rich, and one poor, in carotene.

7. The amount of carotene excreted by rats in their faeces was determined and the percentage of ingested carotene which disappeared (and was presumably absorbed) was calculated.

8. The disappearance of ingested carotene ranged from 33 to $56 \%$ when it was derived from carrots, being least when the concentration in the carrot was greatest; for ordinary carrots it was $47 \%$. When the carotene was derived from oily solution the disappearance ranged from 72 to $78 \%$.

9. The difference between the biological and chemical values can be almost wholly accounted for by the incompleteness of alimentary absorption, and by the lower activity of $\alpha$-carotene which forms an appreciable part of the total carotene in carrots.

Io. The biological value suggested for the vitamin A potency of ordinary carrots, determined in experiments on rats, is $9000 \mathrm{i} . \mathrm{u} . / 100 \mathrm{~g}$.

The carrots rich in carotene were bred and grown by Mr S. O. S. Dark at the Horticultural Research Station, Cambridge. I wish to thank Dr J. Devine for a specimen of pure $\beta$-carotene, Drs L. J. Harris and T. Moore for useful criticism and Messrs A. G. Dockrill and K. R. Symonds for technical assistance. This investigation was begun during the tenure of a Beit Memorial Fellowship and continued during employment by the Agricultural Research Council.

\section{REFERENCES}

Barnès, W. C. (1936). Mem. Cornell agric. Exp. Sta. no. 186.

Booher, L. E., Hewston, E. M. \& Marsh, R. L. (1 94I). Food Res. 6, 493.

Booth, V. H. (1945a). F. Soc. chem. Ind., Lond., 64, I62 T.

Booth, V. H. (1945 b). F. Soc. chem. Ind., Lond., 64, I 94 T.

Broge, J. A. (1945). Om Carotinbestemmelser. Copenhagen: Einar Munksgaard.

Callison, E. C. \& Orent-Keiles, E. (1945). Industr. Engng Chem. (Anal. ed.), 17, 378.

Coward, K. H. \& Morgan, B. G. E. (1935). Brit. med. F. ii, I04I.

Dark, S. O. S. \& Booth, V. H. (1946). Ұ. agric. Sci. 36, 192.

Davies, A. W. (1933). Biochem. F. 27, 1770.

Davies, A. W. \& Moore, T. (1939). Z. Vitaminforsch. 9, 254.

Devine, J., Hunter, R. F. \& Williams, N. E. (1945). Biochem. F. 39, 5 .

Fraps, G. S. \& Meinke, W. W. (1945). Food Res. ro, 187.

Fujita, A. \& Ajisaka, M. (I94I). Biochem. Z. 308, 430.

Graves, H. C. H. (1942). Chem. \& Ind. 6r, 8 .

Guggenheim, K. (1944). Biochem. F. 38, 260.

Hanning, F. (1936). F. Amer. diet. Ass. r2, 23 r.

Harper, R. H. \& Zscheile, F. P. (I945). Food Res. xo, 84.

Hickman, K. C. D., Harris, P. L. \& Woodside, M. R. (1942). Nature, Lond., 150, 91.

Iljina, E. A. (1943). Biachimia, 8, 118.

Kemmerer, A. R. \& Fraps, G. S. (1938). F. Nutrit. 16, 309.

Kemmerer, A. R. \& Fraps, G. S. (1945). Food Res. ro, 457.

Kemmerer, A. R., Fraps, G. S. \& Meinke, W. W. (1945). Food Res. ro, 66.

League of Nations (1934). Quart. Bull. Hlth Org. L.o.N. 3, 432.

Mackinney, G. \& Fratzke, W. E. (1947). Analyt. Chem. r9, 614.

Moore, T. (1945). Vitamins and Hormones, 3, 1.

Moore, T., Martin, A. J. P. \& Rajagopal, K. R. (1939). Vitamin E, a Symposium. Cambridge: W. Heffer and Sons, Ltd.

Morton, R. A. (1942). Absorption Spectra. London: Adam Hilger.

Oser, B. L. \& Melnick, D. (1945). F. Nutrit. 30, 385 .

Ramasarma, G. B. \& Hakim, D. N. (1942). Nature, Lond., 149, 6 I r. 
Sadana, J. C. \& Ahmad, B. (1947). Indian 7. med. Res. 35, 81.

Scheunert, A. \& Wagner, K. H. (1940). Biochem. Z. 303, 208.

Scoular, F. I., Bellew, J. E., Carl, C. J. \& Dozier, V. (1943). F. Amer. diet. Ass. 19, 428.

Smith, M. C. \& Otis, L. (I941). Food Res. 6, I43.

Wagner, K. H., Günther, L. \& Schmalfuss, H. (I943). Vitamine und Hormone, 4, I42.

Wagner, K. H., Günther, L. \& Schulze, L. (1941). Vitamine und Hormone, I, 455.

Werner, H. O. (1 940). Proc. Amer. Soc. hort. Sci. 38, 267.

Wilkinson, H. (r94I). Biochem. F. 35, 824 .

Wilson, H. E. C., Ahmad, B. \& Majumdar, B. N. (1936). Indian F. med. Res. 24, 399.

Wilson, R. H., Ambrose, A. M., DeEds, F., Dutton, H. J. \& Bailey, G. F. (1946). Arch. Biochem. 10, $13 \mathrm{I}$.

Wilson, R. H., Thomas, J. O. \& DeEds, F. (1943). F. Amer. diet. Ass. r9, 428.

With, T. K. (1940). Absorption, Metabolism and Storage of Vitamin A and Carotene. Copenhagen: Einar Munksgaard.

With, T. K. (1942). Vitamine und Hormone, 2, 369.

\title{
Haemoglobin Levels in Pregnancy
}

\section{The Effect of the Rationing Scheme and Routine Administration of Iron}

\author{
BY LUCY WILLS, GLADYS HILL, KAITILIN BINGHAM, \\ MARGARET MIALL AND JOAN WRIGLEY \\ Obstetrical and Pathological Departments, Royal Free Hospital, London
}

(Received I9 April I947)

It has been a medical commonplace for many years that women frequently suffer from a mild degree of anaemia during pregnancy. The anaemia is often referred to as 'physiological' and thought to be associated with the hydraemia which has been shown to occur at this time (Dieckmann \& Wegner, 1934; Thompson, Hirscheimer, Gibson \& Evans, 1938). This theory of a 'physiological' anaemia of pregnancy was based on work on hospital patients who, broadly speaking, were seldom in optimal health, and for some time we had considered the possibility that in the really well-fed woman this anaemia might be absent or negligible. Wartime conditions, by the introduction of the general rationing scheme and particularly by the introduction of special rations for pregnant women, had improved the diet of expectant mothers, especially those of the hospital class. But, though the diet of these women had improved by the end of 1943 , it was still considered low in iron judging by the number of pregnant women with hypochromic anaemia. In order, therefore, to investigate this question of anaemia in pregnancy further, an experiment was started at the end of I943 planned to show the effect on the haemoglobin level and on the general health of the pregnant woman, not only of the improved rations but also of the routine administration of iron. At the same time a fuller blood examination and serial serumprotein estimations were to be done on some of the cases. Unfortunately, a flying bomb incident interrupted the work, but, though the actual numbers of observations were not as large as expected, they were large enough for statistical analysis and are set out briefly in the present paper. 